\title{
Design: Aesthetics as a Promoter of Selling Products in Kosovo
}

\author{
Ariana Gjoni \\ Integrated Design, Fashion Design, University for Business and Technology, UBT, Prishtina, Kosovo \\ Email: ariana.gjoni@ubt.uni.net
}

How to cite this paper: Gjoni, A. (2021). Design: Aesthetics as a Promoter of Selling Products in Kosovo. Open Journal of Business and Management, 9, 1104-1120. https://doi.org/10.4236/ojbm.2021.93059

Received: March 6, 2021

Accepted: May 11, 2021

Published: May 14, 2021

Copyright $\odot 2021$ by author(s) and Scientific Research Publishing Inc. This work is licensed under the Creative Commons Attribution International License (CC BY 4.0).

http://creativecommons.org/licenses/by/4.0/

\begin{abstract}
This research is about the design, aesthetics as a sales promoter in Kosovo and the challenges faced during the production. This research will give insight into design and aesthetics as a promoter of selling products in our country. Preferences, demands and decisions for products are affected by different factors. For a successful sale and differentiation, the product in Kosovo must has the performance, comfort, safety and the ability to be repaired. As for the appearance, the interesting form, the perfect symmetry, the consumers of our country have shown less interest. These findings are important information and the recommendations from this research are important for further success in the field of business, entrepreneurship, economics, fashion design, teaching, etc.
\end{abstract}

\section{Keywords}

Design, Aesthetics, Sales, Product, Differentiation

\section{Introduction}

Analyzing consumer demands for products and services as well as manufacturers' opportunities to offer and meet the demands, desires and needs of consumers, we conclude that consumers, in general, are offered a wide range of products. Therefore, all manufacturers, entrepreneurs, wholesalers, and retailers or fashion designers are in great competition as to who will offer the most desired products on the market. All creators are trying to determine as accurately as possible the factors that influence a product to be the most sought-after one. Today more than ever importance is being paid to the creation of new products. Also, today more than ever more importance is being paid to the appearance of both people and products. The pressure is great because a product has to be liked in many places at the same time. 
Today, due to renewed and changing customer demands as well as technological factors, companies and managers are looking for new strategies to make a difference in their products and services. As competition grows, marketing experts began to focus on new approaches and product innovations to attract the attention of consumers. So we can say that even aesthetics is one of the most effective ways of differentiation. The visual aesthetics of products create value for consumers. Visual aesthetics creates important values for the product and makes it more special. Also, the level of consumer price sensitivity decreases when the product is more unique and prestigious. This study also aims to understand the relationship between product visual aesthetics and consumer price sensitivity.

This research, will prove that design is a necessary dimension of overall product quality and contributes to the successful growth of business services. Functionality, quality and performance of the product often decide on the sale of the product, although even the appearance is what can significantly affect it.

The importance of research lies in the fact that the topic is new and interesting to my country. It's up to date and has to do with a problem that is current as this century is a century of design, new ideas, and branding. It is interesting because this research has not been done before in Kosovo. The importance of the topic lies precisely in the research and the conclusions from this research. The importance of design and aesthetics in the sale of the product will be measured, which is of great importance because it will influence manufacturers and sellers to provide offers that are as close as possible to customer requirements.

1.This research is social and deals with finding, evaluating, or predicting this aspect (sales) and aims to research the driving factors of product sales.

The research was conducted in Kosovo with spontaneous respondents mainly from Prishtina. This research gives us an insight into the design and aesthetics as promoters of product sales in our country. Included are 150 respondents of different ages, 18 - 55 years, representing potential customers of our market. This research is primary because with the questionnaires we applied we aimed to get accurate information about the connection between design, aesthetics and sales. Various factors influence purchasing preferences, demands and decisions. The surveyed customer has expressed more preferences and demands for a product with the best design, so the consumer is ready to buy a functional product before a beautiful product or with a better color, color and aesthetics. Evaluations have been the same regardless of age, gender, status (employed or not), they have gone for the design. A product in our country to promote sales and to be differentiated must have performance, comfort, safety, the possibility of repair. For the appearance, interesting shape, perfect symmetry, the proportion of a product depending on the items, the consumers of our country have shown less interest. These findings and this conclusion are important information for professionals and careers. The recommendations from this research are important for further success in the field of business, entrepreneurship, economics, fashion design, teaching, etc. 
Additional clarification: The research is drafted below in the research literature, ie the value of the design, the specifics of the design products, the principles, the strategies for the qualitative design and the tools, as well as the main components of the products are treated. This section presents the importance of research, questions and hypotheses, research methodology and empirical results. At the end are the conclusions and recommendations.

\section{Literature Review}

\subsection{The Value of Design}

All people are designers. All we do, almost all the time, is design because the design is fundamental to all human activity. Planning and modeling each act for a desired and predictable end constitutes the drafting process. Any attempt to divide design, to make it a thing in itself, is contrary to the inherent value of design as the primary matrix of life (Papanek, 1985). The design should be meaningful and systematically replace the expressions: beautiful, ugly, pleasant, disgusting, unknown, abstract, unknown, and so on. Before there were aesthetic judgments expressed in human culture, individuals were not obliged to discriminate against objects, displaying a kind of justice: a "proper" organization of features, in their structure from other objects that did not have them (Beardsley, 1975). The word "design" is mostly misused and confused with the word "aesthetics". The word design is not so narrow in meaning that it has to do only with decor or aesthetics, design has a much broader definition. To understand what design means, let's refer to the Webster dictionary the first definition of design according to this dictionary: "creation, modification, execution or construction according to plan. This is the essence of what design means, all other definitions are complementary additions (Merriam, 2018).

Design is one of the attributes of the product which contains multiple aspects. It is found throughout the product and is easily perceptible. Its presence during the product creation process enables the adaptation to the needs of buyers. Defining design is very important because of the use of this term. According to systems designer Terence Love, the design has different meanings in different areas. These ambiguities often confuse findings that apply from one field to another. For example, the design definition in medicine indicates a plan or protocol for the care and achievement of the goals, especially of a scientific experiment. For beginners: how something is done, the process of planning what something will look like, drawing something that is planned to be done (Love, 2002). Design is the design of the design to produce a design. (Heskett, 2005) explains how all four uses of design each give a different sense of the word. The first word used as a noun defines the field of design in general. The second use is the verb, which indicates an action. The third use is also a noun, defining a plan or purpose. The fourth use is a noun, this time defining the finished product. Design is a research process to optimize customer satisfaction and company benefits through the creative use of key design elements (performance, quality, sustainability, presen- 
tation, and cost) about products, environments, information, and corporate identities" (Kotler, 2002).

The product design is a creative complex which has to do with the essence and other qualities of the content, internal and external structure (Jakupi, 2008). So, the design is a process that includes other product variables such as functionality, sustainability, usability, economics, etc. Its complexity consists of its content, substance, external form, functionality, usability, and its relations with the environment. But the design cannot be understood only for the whole product. The design also includes size, price, promotion, distribution, etc. Economics and marketing experts early on identified design as a strategic tool, but design was consistently neglected. Although many companies already had their design staff and purchased design services, design many times failed to have an identity in the market (Kotler \& Rath, 1984). This happened because the design failed to be defined correctly but was often misunderstood or not clear enough. For this reason, marketing experts and designers have tried many times to define it.

\subsection{Product Design Specifications}

The main purpose of the design is to create high customer satisfaction and profits for the enterprise. To create a good design, designers try to creatively incorporate the main design elements, namely: performance, quality, durability, appearance, and cost. According to Kotler, these elements can be illustrated in this way (Kotler \& Rath, 1984). Performance, Quality, Durability, Appearance, Cost. But, to divide the designer activities into channels is practically impossible. Defining components as part of design activities aims to explain how the idea has its four parts and the product four individual qualities (Delic, 2016). According to Professor Ali Jakupi, the design should be based on the technical-technological, economic, ergonomic, and aesthetic principles (Jakupi, 2008). For this reason, the design should focus on this goal, on the beautiful side of the product, because it excites, attracts, and seduces it. Without this component, the product would be monotonous, so this component gives the product beauty. This quality is always visible and subject to evaluation. These processes affect the decision-making process in purchasing products temporarily. Adapting the product to the current world fashion is a prerequisite for the acceptance of products in the market (Nikolic \& Desnica, 2018).

The product must also be competitive and efficient, to perform its function, to be aesthetic, economical, and also ergonomic. Creating such a product is a design task. A product creates its character for consumers through design, marketing, and other forms of promotion. The product design should be known as the visual identity of the company and should contribute to the idea that the distributor has of himself.

\subsection{Principles of Product Design}

Design as a function is present in the new product from the beginning, from the 
main idea to the realization and placing on the market. So, when it comes to finding, selecting, and processing an idea, things about the form, functionality, use, and usefulness that the consumer will have (Jakupi, 2008). Creating a new product has to go through a certain design process. This process used to be shorter because the goal was to achieve only technical-technological principles. Today everything is different. To achieve the goals of the enterprise and the customers to remain satisfied, it is necessary to create a product that is required (Papanek, 1985).

Design is variable and non-constant, as it is present in the product in all stages of creation and living (Jakupi, 2008). So, in the new product, the design is present from the idea, design task, design, and production of prototypes to placing on the market. At this stage, it thinks about form, functionality, use, and usefulness. This idea materializes with the production of the prototype where the structural-content dimensions are seen. Then the tests are done which confirm the design level. In the second case, measures are taken about improvement and prosperity.

\subsection{Qualitative Design as a Strategic Tool of Differentiation}

Philip Kotler has defined differentiation as "the act of designing a range of meaningful differences to distinguish the company's offer from competitors' bids" (Kotler, 2002). One framework that has attracted a lot of attention is based on the work of Micheal Porter. The basis of his analysis is that firms identify activities for which they have a competitive advantage over their competitors. Competitive advantage-based strategies can be divided into three general types: cost leadership, differentiation, and focus. When designing to increase aesthetic value, one must take into account the notion that beauty is not only objective and universal according to Emanuel Kant, who argued that: "Beautiful is that which, without a concept such as the concept of good, is universally liked." This universality is the aesthetic amount of a judgment of taste and is what distinguishes it from judgments of the pleasant. But this universality is only "subjective": judgment requires all subjects to give their consent to judgment (Kant \& Pluhar, 2002).

\subsection{Aesthetics as the Main Components of the Product}

Before the existence of aesthetic judgments expressed in human culture, individuals were not obliged to discriminate against objects, displaying a "proper" organization of features, in their structure from other objects that they did not have. However, from a phenomenological point of view, there has been at least undefined interest in some objects, rather than others. The problem of justice arose when the humanities scholars tried to explain our interest in some objects (instead of others) in terms of aesthetic values and properties associated with "ideals" about beauty and ugliness, which provoke pleasure and dissatisfaction to a receptor (Beardsley, 1975). Design components are some features that make up 
the design process, through its stages and activities in which the product is created. If we look at the practical side, design components are factors in product quality. Thus, in practical terms, the design components represent the flow of activities of the design process. This aspect is more important than the theoretical one. Total quality consists of four individualities, which are integrated into total quality. Therefore, the design components and the quality of the product are closely related and at the same time are the essential feature of creativity and overall design performance. The aesthetic component goes through the set of activities in the design process, the quality of aesthetic products (Nikolić \& Desnica, 2018).

It has been proven experimentally that a person in visual communication with objects in a concrete case notices with the order: size, shape, colors, ornament (Nikolić \& Desnica, 2018).

Size - Every object in nature has spatial dimensions or dimensions. If a product has harmony in its size it strongly affects the emotions of people and thus the value belongs to the order of high aesthetics. All sizes of objects used by a person should be adapted to its anatomical structures. Therefore, size is one of the basic elements of the product. The size of each product in the design must follow the ergonomic purpose and human requirements. Nothing can be "big" or "small". Size will affect aesthetic quality only if it is incorporated into the product through quality materials and if it is worked solidly in the technological process.

Shape - In economics objects must have a shape that is limited in space. These boundaries are defined through visual contours, lines and surfaces which the human eye sees under the action of light. The forms that are natural creations and that man sees every day, act in the human psyche without his will. While those forms which he creates are subject to his will and aesthetic requirements. In design and art it is believed that the most sophisticated forms are in nature. Therefore, the most sophisticated shapes that a person can create are those sizes, colors and ornaments which approach the shapes of nature.

Colors - The materials from which the products are made have their natural color, but it can change and different colors and tones can be applied. With this product can achieve a higher aesthetic quality. Colors in general are very important to people because they react to them. They express a psychological reaction in people. The colors and shape of the product should be in harmony with each other and fit as a single whole. Also, the color of the products pursues a goal, depending on the function, gender, age or habits of the consumer. Therefore, the colors of clothes and shoes, furniture and facades, environments, etc. should be harmonized. Color is often the deciding factor in consumer purchasing decisions.

Ornaments are used to enhance the aesthetic quality of products. If they are enriched with decorations and details, then the products are more beautiful. But, excessive use distorts the aesthetic quality of the product. The use of jewelry is closely related to the function and nature of the product. Usually, ornaments are used for clothing or furniture, bypassing the white technique, etc. This too 
should be planned to what extent it should be decorated, it should also be decorated according to a psychological measure. This has to do with different cultures and people. People of low culture and education also, tend to be primitive in the decorations they use (Nikolić \& Desnica, 2018). A study entitled "The Effect of Visual Product Aesthetics on Consumer Sensitivity to Price" by Jigit Mumcu and Halil Semih Kimzanb, has found that there is a strong negative correlation between product visual aesthetics and consumer sensitivity to prices. This means that when the design of a product is impressive and powerful, consumers will be less sensitive to the price of the product (Mumcu \& Halil, 2015). "Impressive product designs will be able to reduce the level of price sensitivity. This can strengthen the economic aspect of companies. In light of this information, product aesthetics enable companies to have higher profits," Product Aesthetics visual is very important not only in terms of consumer behavior but also from corporate identity and brand image" (Mumcu \& Halil, 2015).

Modern marketing theories see marketing as an economic process derived from the rich practices of industrialized countries; provide a good basis for the view that the application of marketing as a business function should ensure a harmonious relationship between production and consumption, and filling and market research. According to Philip Kotler, the first step of marketing specialists is to know the requirements and needs of customers and the market in which they operate. So, the basic concept on which marketing is based is that of people's needs. Philip Kotler defines marketing as a social and managerial process through which individuals and organizations provide what they need and want, through value creation and exchange (Kotler, 2002). The definition of a marketing mix is simple. It is about putting the right product or a combination of them in the right place, at the right time, and the right price. This is the hard part and only succeeds if we know every aspect of the company's business plan (Acutt, 2015). A marketing expert named E. Jerome McCarthy created Marketing 4Ps in the 1960s. This classification is used all over the world. Business schools teach this concept in basic marketing classes (Acutt, 2015).

Throughout history, the price was the result of a conversation between a seller and a buyer. There was a discussion and in the end, and an intermediate price was set. A fixed price for items is a relatively new idea that has found wide application in modern commerce. But in recent years other factors have emerged that are becoming increasingly important, such as publicity, promotion, sales, etc. (Bardhyl, 2006). According to Kotler, sales promotion, a key component of a marketing campaign, consists of the collection of incentives, mainly short-term, designed to stimulate faster or greater purchases of certain products or services by consumers or the market. So, even if the product is attractive to the consumer, non-coordination in promotion actions can call into question the whole efficiency of the enterprise (Kotler, 2002).

According to Professor Ali Jakupi, consumer behaviors are the result of the lack of something, of births and conditional acquisitions, of influences from 
various factors. They are very important before planning and designing new products. Factors that influence consumer behavior are divided into three groups: cultural, social, and personal factors. Motivation, man has many needs which are biological and psychological. A motive is a need that drives the person to seek its fulfillment. Motivation is influenced by perception because it is a process by which an individual creates an image of something, in this case for a product or service (Kotler, 2002).

\section{Research}

The purpose of the research is to test the design and aesthetics in selling the product. What is their relationship? Will it be researched whether to sell more a product with better designs and aesthetics by employed or unemployed, women or men, or a product with simpler designs, taking into account the economic conditions and standard of living in Kosovo?

\subsection{Research Question and Hypothesis}

The questions posed in this paper are:

- Is there a connection between the product, the design, the sale?

- Are there connections between the product, aesthetics, and sales?

- Which designed products are highly valued?

- What is most valued in a product when consumers buy products?

- Are there differences between demographic parameters and their opinion on design evaluation and aesthetics?

The research will present the relationship between design concepts, aesthetics, and sales. The main objective of this paper is to validate the hypotheses as follows:

H01. Good product design drives its sales.

H02. Aesthetics has a greater connection with product sales.

H03. There is a connection between design, aesthetics and purchasing the product.

H04. There are significant differences between the gender and age of respondents concerning the opinion on design and aesthetics.

The hypotheses have been validated through the Pearson Chi-square which gives us an overview of the respondents' opinion regarding the assertions, and the results are seen in the following tables (Tables 1-4).

\subsection{Methodology}

Research is social and deals with finding, evaluating, or predicting this aspect (sales) and aims to research the driving factors of product sales.

Short evaluation: qualitative research. Given the nature of the research, data was collected through a questionnaire which was conducted online. Also, this research will be primary as the questionnaire that was applied will aim to get as much knowledge as possible about how design and aesthetics influence as a mo- 
tivator in the purchase, respectively the sale of a product. The questionario was designed to get informations and opinions from people's experiences with purchases.

1) The questionnaire was compiled to provide sufficient information about the production, design, needs, and preferences of customers. Methods of data analysis, we present the data that was collected through formulated questionnaires. From these results, the importance of design and aesthetics in selling the product, target market where we should focus in the future, customer requirements.

2) Based on the hypotheses of this research paper, the questions of the respondents were designed to understand how design and aesthetics have an impact on sales promotion, as well as to understand the behavior of consumers concerning the messages presented as their offer.

3) The sample was calculated using the formula.

$$
\text { Sample size }=\frac{\frac{z^{2} \times p(1-p)}{e^{2}}}{1+\left(\frac{z^{2} \times p(1-p)}{e^{2} N}\right)}
$$

In summary, there are three main arguments identified that justify the implementation of research, design is a key factor in the financial performance of the manufacturing or sales enterprise, good design demanded by customers because it differentiates, good design as a marketing strategy proven to be successful.

\section{Empiric Results}

A total of 147 respondents participated in the research, of which 98 were female or $66.7 \%$, while 49 were male or $33.3 \%$. Of the 18 - 25 age group were 56 respondents or $38.1 \%, 43$ were of the 26 - 35 age group or $29.3 \%, 44$ of the $36-45$ age group or $29.9 \%$ and 4 were of the 46 - 55 age group or $2.7 \%$.

Employees were 91 respondents or $61.9 \%$, while 56 unemployed or $38.1 \%$, while 99 of them say that they often buy products or $67.3 \%, 47$ say that they do not buy very often or $32 \%$ and 1 says that this rarely happens or $0.7 \%$.

We understand that 104 respondents or $70.7 \%$ are dissatisfied with the products offered in Kosovo, on average 40 or $27.2 \%$ are satisfied and a very small number 3 of them or $2 \%$ are very satisfied. What they value most in products when buying is design and performance with $64.6 \%$, while aesthetics is $35.4 \%$.

The results show that consumers spend the most money on clothing with $39.5 \%$, technology $7.5 \%$, on services, beauty products $2.7 \%$, while the best design is estimated at $72.1 \%$, while aesthetics and appearance with $25.2 \%$. Most design is valued at clothing with $42.9 \%$, technology with $8.8 \%$, and service with $4.8 \%$. The proportion of design with aesthetics in the products possessed by consumers is with $8.2 \%$ have chosen the proportion $20-80,15 \%$ the proportion $50-50$ and $26.5 \%$ the proportion $60-40$. 
Table 1. Sample of respondents based on age, gender and employment.

\begin{tabular}{ccc}
\hline Gender & N & $\%$ \\
\hline Female & 98 & 66.7 \\
Male & 49 & 33.3 \\
\hline Age & N & $\%$ \\
\hline $18-25$ & 56 & 38.1 \\
$26-35$ & 43 & 29.3 \\
$36-45$ & 44 & 29.9 \\
$46-55$ & 4 & 2.7 \\
\hline Employment & N & $\%$ \\
\hline Yes & 91 & 61.9 \\
No & 56 & 38.1 \\
\hline How often do you buy products & N & $\%$ \\
\hline Often & 99 & 67.3 \\
Not very often & 47 & 32.0 \\
Rarely & 1 & 0.7 \\
\hline
\end{tabular}

Table 2. Respondent product evaluation.

\begin{tabular}{lcc}
\hline How satisfied are you with the products offered by the Kosovo market? & $\mathrm{N}$ & $\%$ \\
\hline Dissatisfied & 104 & 70.7 \\
Moderately satisfied & 40 & 27.2 \\
Very satisfied & 3 & 2.0 \\
\hline What do you value most when you buy a product? & $\mathrm{N}$ & $\%$ \\
\hline Design-performance & 95 & 64.6 \\
Esthetics & 52 & 35.4 \\
\hline Which products do you spend the most money on? & $\mathrm{N}$ & $\%$ \\
\hline Clothes & 58 & 39.5 \\
Technology & 11 & 7.5 \\
Service & 9 & 6.1 \\
Beauty products & 4 & 2.7 \\
\hline Would you pay more for a product for a better design or more beautiful aesthetics? & $\mathrm{N}$ & $\%$ \\
\hline The best design & 106 & 72.1 \\
Aesthetically more beautiful & 37 & 25.2 \\
Which products do you value the design the most? & & 73 \\
Clothes & 63 & 42.9 \\
\hline Technology & 13 & 8.8 \\
\hline
\end{tabular}


Continued

\begin{tabular}{lcc}
\hline What is the proportion of products with the best design/aesthetics in your home? & $\mathrm{N}$ & $\%$ \\
\hline $20-80$ & 12 & 8.2 \\
$50-50$ & 22 & 15.0 \\
$60-40$ & 39 & 26.5 \\
\hline Is there a connection between design and aesthetics for purchasing the product? & $\mathrm{N}$ & $\%$ \\
\hline Yes & 103 & 70.1 \\
No & 44 & 29.9 \\
\hline $\begin{array}{l}\text { In the products you buy and consume, is there a connection between } \\
\text { the design and the decision to purchase the product? }\end{array}$ & $\mathrm{N}$ & $\%$ \\
\hline Yes & 119 & 81.0 \\
No & 28 & 19.0 \\
\hline Does improving the design or changing the aesthetics of the product increase sales? & $\mathrm{N}$ & $\%$ \\
\hline Agree & 110 & 74.8 \\
I do not agree & 21 & 14.3 \\
Neutral & 16 & 10.9 \\
\hline
\end{tabular}

Over $70 \%$ of respondents think that there is a connection between design and aesthetics, while $29.9 \%$ do not believe such a thing, while over $80 \%$ say that there is a connection between design and their decision to buy a product. While they think that product design and aesthetics have an impact on product sales with $74.8 \%, 14.3 \%$ disagree, while $10.9 \%$ are neutral.

To present a clearer analysis, we also used the Chi-Square test, where we made distinctions between demographic parameters and responses related to the research question.

The Chi-Square test was conducted for the demographic parameters of gender and age, where based on the results of gender we see that in the vast majority we have significant differences between men and women in terms of their opinion on design and aesthetics, while in three cases there are no differences, precisely in their satisfaction with the products offered in Kosovo, whether they would pay more for a better design and in their opinion that there is a connection between design and aesthetics. With this we can say that there are partially significant differences between men and women concerning their opinion on the design and aesthetics of products in Kosovo, p-value $<0.05 \%$ and $<0.01 \%$.

In the age we see that we have significant differences in all cases there are significant differences p-value $<0.01 \%$.

The correlation analysis below presents the importance of age as an important factor in determining the decision for product design and aesthetics.

Based on the above results we see that old age has a significant impact on the opinion of respondents on the evaluation of aesthetics, design, and decision to buy them, p-value $<0.01 \%$ and $<0.05 \%$. In this case, we can conclude that gender, 
Table 3. Design - Aesthetics based on demographic parameters of gender and age.

\begin{tabular}{|c|c|c|}
\hline Gender & Pearson Chi-square & P-value \\
\hline How often do you buy products & 6.983 & 0.030 \\
\hline How satisfied are you with the products offered by the Kosovo market? & 1.832 & 0.400 \\
\hline What do you value most when you buy a product? & 10.058 & 0.002 \\
\hline Which products do you spend the most money on? & 16.568 & 0.002 \\
\hline Would you pay more for a product for a better design or more beautiful aesthetics? & 3.806 & 0.149 \\
\hline Which products do you value the design the most? & 21.542 & 0.000 \\
\hline What is the proportion of products with the best design/aesthetics in your home? & 22.884 & 0.000 \\
\hline Is there a connection between design and aesthetics for purchasing the product? & 0.259 & 0.703 \\
\hline $\begin{array}{l}\text { In the products you buy and consume, is there a connection between the design } \\
\text { and the decision to purchase the product? }\end{array}$ & 18.551 & 0.000 \\
\hline Does improving the design or changing the aesthetics of the product increase sales? & 40.605 & 0.000 \\
\hline Age & Pearson Chi-square & P-value \\
\hline How often do you buy products & 114.950 & 0.000 \\
\hline How satisfied are you with the products offered by the Kosovo market? & 157.391 & 0.000 \\
\hline What do you value most when you buy a product? & 40.563 & 0.000 \\
\hline Which products do you spend the most money on? & 190.646 & 0.000 \\
\hline Would you pay more for a product for a better design or more beautiful aesthetics? & 61.783 & 0.000 \\
\hline Which products do you value the design the most? & 131.424 & 0.000 \\
\hline What is the proportion of products with the best design/aesthetics in your home? & 93.314 & 0.000 \\
\hline Is there a connection between design and aesthetics for purchasing the product? & 19.293 & 0.000 \\
\hline $\begin{array}{l}\text { In the products you buy and consume, is there a connection between the design } \\
\text { and the decision to purchase the product? }\end{array}$ & 17.850 & 0.000 \\
\hline Does improving the design or changing the aesthetics of the product increase sales? & 74.500 & 0.000 \\
\hline
\end{tabular}

Table 4. Consumer buying decision by age for product design and aesthetics.

\begin{tabular}{lcc}
\hline \multicolumn{1}{c}{ Age } & Pearson Correlation & P-value \\
\hline How often do you buy products & $0.640^{* *}$ \\
How satisfied are you with the products offered by the Kosovo market? & $0.503^{* *}$ & $0.803^{* *}$ \\
What do you value most when you buy a product? & $0.611^{* *}$ & 0.000 \\
Which products do you spend the most money on? & $0.646^{* *}$ & $0.458^{* *}$ \\
Would you pay more for a product for a better design or more beautiful aesthetics? & $0.684^{* *}$ & 0.000 \\
Which products do you value the design the most? & $0.355^{* *}$ & 0.000 \\
What is the proportion of products with the best design/aesthetics in your home? & $0.171^{*}$ \\
Is there a connection between design and aesthetics for purchasing the product? & 0.000 \\
In the products you buy and consume, is there a connection between the design & 0.000 \\
and the decision to purchase the product? & 0.038 \\
Does improving the design or changing the aesthetics of the product increase sales? & 0.000 \\
\hline
\end{tabular}


age in most cases are important factors and determine the form of choice of design and aesthetics as an important factor for the purchase of products.

\section{Conclusion}

The citizens of Kosovo are moderately satisfied with the Kosovo market, they often buy different items, clothing, fewer technology items, while they spend less on beauty products.

This conducted survey showed that the design has led to all test results. Respondents have shown that especially in clothing they choose a product with the best design. But research has also shown that consumers of our country also demand their aesthetics from clothing. This proves to us that design and aesthetics are interrelated.

From the data analysis, we also find that design influences buyers' decision to buy a product, and we conclude that the aesthetic side and product design need to be improved and renovated to succeed in increasing sales of various goods.

Taking into account the gender analysis, the findings also show that women and men are moderately satisfied with the Kosovo market, the design is the one that is most appreciated by the products. From findings we conclude that women tend to look for the aesthetic side of the product at the same time when buying clothing items, while men with a small margin are declared for clothing and technology.

The research also shows that even based on the economic status of the employed and unemployed, they also value functional products more, prefer being willing to pay more for quality and comfortable clothing.

Analyzing the data by age group, we have the result in favor of the design. We conclude that all age groups want quality and functional products. The second age group, 26 - 35 years old, unemployed people rarely buy, unlike employees who often buy and appreciate the design.

Analyzing the results of the conducted research, we have concluded that consumers in our country between a product with the best design or aesthetics have chosen the product with the best design. They are willing to pay more for a product that has the best design.

This research has proven that design activity and marketing research are reflected in the quality, functionality, and optimality of the product. Due to the rising standard of living today's consumer has been refurbished; its product requirements have changed. They now expect and demand a high quality or superior product.

As we have said above, the aesthetic quality of the buyer's decision to buy a product depends on the level of education and culture, the level of information, purchasing power, different experiences in using the products, etc. We have also said above that "the appearance of the product often decides to sell the product, even though performance is what can have a significant impact."

This study provides opportunities for further research on the role of product 
design and aesthetics and for manufacturers, designers. Research should continue by applying comparative analysis to foreign trends to define new strategies for the production and processing of products for the needs of the industry.

\section{Recommendations}

Kosovo market should be enriched with new inflows and a variety of goods which are current, modern and up to date.

For manufacturers and creators of new products, design and aesthetics should focus on the comfort and beautiful side of the products because it excites, attracts, and seduces the consumer.

Small and large manufacturing, trading, and service companies are recommended creating or offering products, goods, and services that are functional, quality, and safe.

All designers: fashion designers, creators of new products should be engaged and involved to meet the needs and satisfaction of customers with special emphasis on design.

Fashion designers and fashion houses should create or bring clothes with modern and timeless designs. Fashion items or clothing at the same time should be comfortable, quality, and aesthetically beautiful to stay longer in the market.

The design should be defined as the objective of an enterprise, manufacturer and designers to achieve the power it brings.

Marketing experts and those who have interests in the field of design attract and encourage entrepreneurs, manufacturers, traders for functionality, safety, and the ability to repair products.

The design in the marketing of an enterprise should be an integrated part and planned.

The product design should be improved or changed to products in which the design has become obsolete or has become sensitive to competition.

Design is a powerful strategic tool that companies must use to gain a competitive advantage.

Manufacturing companies design as components of products should not be overlooked or neglected during the production process.

The main contribution of this research paper are the final results were the importance of design and aesthetics in the sale of the product will be measured and which will influence the manufacturers, entrepreneurs, fashion designers, marketing experts and people from the industry to offer as many offers as possible, according to customer requirements in general.

\section{Conflicts of Interest}

The author declares no conflicts of interest regarding the publication of this paper.

\section{References}

Acutt, M. (2015). Marketing Mix Definition-4Ps \& 7Ps of the Marketing Mix. Mark Acutt 
\& Patrick Kuo, 1 .

Bardhyl C Nail, R. (2006). Marketing (pp. 133-135). Prishtina-Kosovo: Iliria University-Prishtinw.

Beardsley, M. C. (1975). Aesthetics from Classical Greece to the Present: A Short History (Studies in the Humanities) (pp. 21-22.). Tuscaloosa, AL: University of Alabama Press.

Delic, M. (2016). DIZAJNIRANJE PROIZVODA U PODUZEĆU “NAPRIJED” D.O.O., SINJ. Lecture, Split.

Heskett, J. (2005). Design: A Very Short Introduction (p. 3). Oxford: Oxford University Press. https://doi.org/10.1093/actrade/9780192854469.001.0001

Jakupi, A. (2008). Marketingu (bazat)-Prishtinw (pp. 361-363). Universiteti AAB: Fakuteti Ekonomik.

Kant, I., \& Pluhar, W. S. (2002). Critique of Practical Reason (pp. 211-212). Indianapolis, IN: Hackett Publishing Company, Inc.

Kotler, P. (2002). Marketing Management Millenium Edition (10th ed.). Upper Saddle River, NJ: Pearson Education Company.

Kotler, P., \& Rath, G. A. (1984). Design: A Powerful but Neglected Strategic Tool. Journal of Business Strategy, 5, 16-21. https://doi.org/10.1108/eb039054

Love, T. (2002). Constructing a Coherent Cross-Disciplinary Body of Theory about Designing and Designs: Some Philosophical Issues. Design Studies, 23, 345-361. https://doi.org/10.1016/S0142-694X(01)00043-6

Merriam, W. (2018). Definition of DESIGN.

https://www.merriam-webster.com/dictionary/design

Mumcu, Y., \& Kimzan, H. S. (2015). The Effect of Visual Product Aesthetics on Consumers' Price Sensitivity. Procedia Economics and Finance, 26, 528-534. https://doi.org/10.1016/S2212-5671(15)00883-7

Nikolić, M. D. E. (2018). Industrijski Dizajn. Tehnicki fakultet “Mihajlo Pupin”.

Papanek, V. (1985). Design for the Real World: Human Ecology and Social Change (pp. 3-4). Chicago, IL: Academy Chicago Publishers. 


\section{Appendix}

\section{Survey Questionnaire on:}

Design - Aesthetics as a Promoter of Selling Products in Kosovo

1. Gender

o Male

o Female

2. Age
o $18-25$
o $26-35$
o $36-45$
o $46-55$

3. Employment

o Yes

o No

4. How often do you buy products

o Often

o Not very often

o Rarely

5. How satisfied are you with the products offered by the Kosovo market?

o Dissatisfied

o Moderately satisfied

o Very satisfied

6. What do you value most when you buy a product?

o Design-performance

o Esthetics

7. Which products do you spend the most money on?

o Clothes

o Technology

o Service

o Beauty products

o Others

8. Would you pay more for a product for a better design or more beautiful aesthetics?

o The best design

o Aesthetically more beautiful

9. Which products do you value the design the most?

o Clothes

o Technology

o Service

o Beauty products 
o Others

10. Which are the products that you value aesthetics the most?

o Clothes

o Technology

o Service

o Beauty products

o Others

11. What is the proportion of products with the best design/aesthetics in your home?

o $20-80$

о 50 - 50

0 $60-40$

12. Is there a connection between design and aesthetics for purchasing the product?

o Yes

o No

13. In the products you buy or consume, is there a connection between the design and the decision to purchase the product?

o Yes

o No

14. Does improving the design or changing the aesthetics of the product increase sales?

o Agree

o I do not agree

o Neutral

Thank you for your time and cooperation! 